\title{
Research
}

\section{Long-term oral prednisolone exposure in primary care for bullous pemphigoid:}

\author{
population-based study
}

\begin{abstract}
Background

Oral prednisolone is the mainstay treatment for bullous pemphigoid, an autoimmune blistering skin disorder affecting older people. Treatment with moderate-to-high doses is often initiated in secondary care, but then continued in primary care.

\section{Aim}

To describe long-term oral prednisolone prescribing in UK primary care for adults with bullous pemphigoid from 1998 to 2017

\section{Design and setting}

A prospective cohort study using routinely collected data from the Clinical Practice Research Datalink, a primary care database containing the healthcare records for over 17 million people in the UK
\end{abstract}

\section{Method}

Oral prednisolone exposure was characterised in terms of the proportion of individuals with incident bullous pemphigoid prescribed oral prednisolone following their diagnosis, and the duration and dose of prednisolone.

\section{Results}

In total, 2312 (69.6\%) of 3322 people with bullous pemphigoid were prescribed oral prednisolone in primary care. The median duration of exposure was 10.6 months (interquartile range [IQR] 3.4-24.0). Of prednisolone users, $71.5 \%$ were continuously exposed for $>3$ months, $39.7 \%$ for $>1$ year $14.7 \%$ for $>3$ years, $5.0 \%$ for $>5$ years, and $1.7 \%$ for $>10$ years. The median cumulative dose was 2974 mg (IQR 1059-6456). Maximum daily doses were $\geq 10 \mathrm{mg} /$ day in $74.4 \%$ of prednisolone users, $\geq 20 \mathrm{mg} /$ day in $40.7 \%$, $\geq 30 \mathrm{mg} /$ day in $18.2 \%, \geq 40 \mathrm{mg} /$ day in $6.6 \%$, $\geq 50 \mathrm{mg} /$ day in $3.8 \%$, and $\geq 60 \mathrm{mg} /$ day in $1.9 \%$.

\section{Conclusion}

A high proportion of people with incident bullous pemphigoid are treated with oral prednisolone in UK primary care. Action is required by primary and second care services to encourage use of steroid-sparing alternatives and, where switching is not possible, ensure prophylactic treatments and proactive monitoring of potential side effects are in place.

\section{Keywords}

bullous pemphigoid; Clinical Practice Research Datalink; corticosteroid; prednisolone;

prescriptions; primary health care.

\section{INTRODUCTION}

Bullous pemphigoid is an autoimmune skin disease, characterised by the formation of intensely itchy blisters, which largely affects older people. Approximately 3500 people are diagnosed with bullous pemphigoid for the first time in England every year, and the diagnosis is associated with approximately three-times increased risk of death in the first 2 years. ${ }^{1,2}$ Additionally, the diagnosis is associated with increased risk of autoimmune conditions (for example, systemic lupus erythematosus), neurological conditions (for example, Parkinson's disease), cardiovascular conditions (for example, hypertension), and other skin conditions (for example, psoriasis). ${ }^{3-5}$

Oral prednisolone has traditionally been the first-line systemic treatment for bullous pemphigoid for decades. ${ }^{6,7}$ In recent years, the benefit of safer alternatives has been demonstrated including super-potent topical corticosteroids and anti-inflammatory antibiotics (for example, doxycycline) 8., $^{8,9}$ but systemic steroids are still widely used. Although effective, prednisolone exposes an already vulnerable group to an increased risk of conditions such as osteoporosis and diabetes. ${ }^{10,11}$ Patients may be started on moderate-to-high doses of oral prednisolone in primary or secondary care settings. Patients referred onwards to secondary

MSM Persson, PhD, research fellow; KE Harman $\mathrm{PhD}$, associate professor of applied dermatology research; KS Thomas, PhD, professor of applied dermatology research; S Gran, PhD, assistant professor; JR Chalmers, PhD, senior research fellow, Centre of Evidence Based Dermatology, School of Medicine, University of Nottingham, Nottingham. Y Vinogradova, PhD, senior research fellow, Division of Primary Care, University of Nottingham, Nottingham. SM Langan, PhD, professor of clinical epidemiology, Department of Non-communicable Disease Epidemiology, London School of Hygiene and Tropical Medicine, London. J Hippisley-Cox, PhD, professor of clinical epidemiology and general practice, Nuffield Department of Primary Care Health care for diagnosis and treatment of bullous pemphigoid typically have their long-term management shared jointly between primary and secondary care teams.

Characterising oral prednisolone exposure allows us to better understand the iatrogenic risks for people with bullous pemphigoid. The long-term use in this population is poorly understood, and the little available evidence is based on small studies involving hospital-based patients (Table 1). ${ }^{12-22}$ Routinely collected health data from primary care, in the form of the Clinical Practice Research Datalink (CPRD), provides an opportunity to address this research gap using a large population-based sample that is broadly representative of the UK. ${ }^{23}$ This study examines prescriptions for oral prednisolone issued in UK primary care for incident cases of bullous pemphigoid.

\section{METHOD}

\section{Study design and data source}

This was a prospective cohort study using routinely collected health data from the CPRD. The CPRD is a longitudinal database of UK general practices containing the anonymised diagnosis, referral, prescription, and vaccination data of approximately 17 million people, with a current coverage of approximately 2.7 million (4\%) of the UK population. Although bullous pemphigoid is

Sciences, University of Oxford, Oxford. Address for correspondence

Sonia Gran, Centre of Evidence Based Dermatology, School of Medicine, University of Nottingham, Nottingham NG7 2NR, UK. Email: sonia.grananottingham.ac.uk

Submitted: 21 September 2020; Editor's response: 5 February 2021; final acceptance: 17 May 2021.

\section{CThe Authors}

This is the full-length article (published online 5 Oct 2021) of an abridged version published in print. Cite this version as: $\mathbf{B r} \mathbf{J}$ Gen Pract 2021; DOI: https://doi.org/10.3399/BJGP.2020.0870 


\section{How this fits in}

Bullous pemphigoid is an autoimmune blistering skin disorder that generally affects older people and is associated with a threefold increase in mortality. Although oral prednisolone has been considered the mainstay of treatment for decades, its long-term use in primary care is poorly characterised. This study found that 70\% of people with incident bullous pemphigoid were prescribed oral prednisolone in primary care, at considerable doses and durations of exposure. As they may be on oral prednisolone for prolonged periods of time, conversations between primary and secondary care physicians involved in their care should address steroid-sparing alternatives and, when switching is not possible, ensure prophylactic treatment Ifor example, bone-sparing treatments) and proactive monitoring of side effects are in place.

predominantly diagnosed in secondary care, the diagnosis is subsequently transcribed from discharge or specialist clinic letters into the CPRD using Read codes. ${ }^{24}$

For this study only practices recording data using VISION software (CPRD GOLD) were used. The data in the CPRD have repeatedly been shown to be of good research quality. ${ }^{25}$ At the practice level, participating practices are audited to confirm data quality. At the patient level, records are assessed and data checks are conducted to ensure that the record meets prespecified quality standards.

This work follows the REporting of studies Conducted using Observational Routinely collected health Data (RECORD) guidelines. ${ }^{26}$ The data can be requested from www.cprd.com.

\section{Study population}

The study population comprised adult males and females with incident bullous pemphigoid diagnoses between January 1998 and December 2017, selected using previously described methods. ${ }^{1,27}$ In short, a validated algorithm was implemented to identify people with a code for bullous pemphigoid (M145), pemphigoid (M145.00), or pemphigoid NOS (not otherwise specified, M145z00) in their clinical records. This approach has a positive predictive value of $93.2 \%(95 \%$ confidence interval $[\mathrm{Cl}]=91.3 \%$ to $94.8 \%$..$^{27}$ The bullous pemphigoid index date was the date the diagnosis was first recorded.

To identify people for whom prednisolone might have been prescribed for alternative indications, only people with at least 12 months' data before the bullous pemphigoid index data were eligible. In order to allow sufficient time to capture prescriptions lunder the assumption that initial treatment would be prescribed in secondary care and therefore would not appear in the CPRD), people with $<6$ months' follow-up after their bullous pemphigoid index date were excluded.

\section{Observation period}

People were followed up from their bullous pemphigoid index date until the earliest of the date: 1) the person left the practice; 2) the person died; 3 ) the practice last contributed data to the CPRD; or 4) 31 December 2017.

\section{Oral prednisolone prescriptions}

All prescriptions for oral prednisolone (see Supplementary Table S1 for Read codes) during the observation period were identified. This study focused only on prescriptions issued after the bullous pemphigoid index date based on the assumption that these would reflect long-term management following the diagnosis.

Prednisolone dose and duration were extracted when available and imputed when missing. These data were often missing when prescriptions were issued with information restricted to the free-text field, such as 'Take as indicated by your dermatologist'. Implausible and missing values were handled using the DrugPrep algorithm, ${ }^{28}$ with the decisions described and validated by Joseph et a ${ }^{29}$ (see Supplementary Table S2). Cleaning oral glucocorticoid prescriptions in this way has been found to have a sensitivity of $84.2 \%(95 \% \mathrm{Cl}=68.7 \%$ to $94.0 \%)$ and a specificity of $87.5 \% \quad(95 \% \mathrm{Cl}=73.2 \%$ to 95.8\%) for predicting patient-reported current glucocorticoid use. ${ }^{29}$

\section{Alternate indications for oral prednisolone}

Oral prednisolone can be prescribed for other indications besides bullous pemphigoid, such as rheumatoid arthritis or asthma. To understand the proportion of people who may have been prescribed prednisolone for reasons other than bullous pemphigoid, those with a Read code for an alternative indication in the 12 months preceding their bullous pemphigoid index date were identified. The code lists were drawn from Kuan et a ${ }^{30}$ (see Supplementary Table S3).

\section{Statistical analysis}

The proportion of people prescribed oral prednisolone following their bullous 
Table 1. Proportion of patients with bullous pemphigoid exposed to oral prednisolone as presented in published studies, presented alongside dose and duration information

\begin{tabular}{|c|c|c|c|c|c|c|c|}
\hline Publication & Country & Setting & Years & $n$ & $\begin{array}{l}\text { Treatment } \\
\text { timing }\end{array}$ & $\begin{array}{l}\text { Patients on oral } \\
\text { prednisolone, } \%\end{array}$ & Additional dose and duration detail \\
\hline Balestri et al (2018) ${ }^{12}$ & Italy & Clinic & $2008-2012$ & 53 & Initial & 96.2 & Dose range: $0.5-0.75 \mathrm{mg} / \mathrm{kg} /$ day \\
\hline Kremer et al (2017)13 & Israel & Hospital & $2008-2014$ & 104 & Initial & 78.1 & $\begin{array}{l}\text { Mean dose: } 57.3 \text { mg/day (range } \\
30-70 \mathrm{mg} / \text { dayl }\end{array}$ \\
\hline Zhang et al (2013) $)^{14}$ & China & Hospital & $2005-2010$ & 94 & Initial & 85.0 & Maximum dose: range $20-80 \mathrm{mg} /$ day \\
\hline Esmaili et al (2012) $)^{15}$ & Iran & Hospital & $1987-2007$ & 122 & Initial & 73.8 & $\begin{array}{l}\text { Mean dose: } 60.38 \text { mg/day (SD } 21.21 \text {, } \\
\text { range } 5-120 \text { mg/dayl }\end{array}$ \\
\hline Kulthanan et al (2011)16 & Thailand & Clinic & $1991-2009$ & 58 & Initial & 89.7 & $\begin{array}{l}\text { Mean cumulative dose to achieve } \\
\text { remission: } 0.05 \mathrm{~g} / \mathrm{kg}\end{array}$ \\
\hline Serwin et al (2007) ${ }^{17}$ & Poland & Hospital, clinic & $2000-2005$ & 35 & Initial & 68.6 & Dose range: $40-60$ mg/day \\
\hline Nanda et al (2006) $)^{18}$ & Kuwait & Clinic & $1991-2005$ & 41 & Initial & 100 & - \\
\hline Tan and Tay (2018) ${ }^{19}$ & Singapore & Hospital & $2004-2012$ & 100 & Any time & 96.0 & $\begin{array}{l}\text { Mean duration: } 11.6 \text { months (range } \\
1 \text { week to } 60 \text { months) }\end{array}$ \\
\hline Chang et al (1996) $)^{21}$ & Taiwan & Hospital & 1977-1994 & 86 & Initial & 83.7 & Mean dose: $54.1 \mathrm{mg} / \mathrm{day}$ \\
\hline Garcia-Doval et al (2005) $)^{22}$ & Spain & Hospital & 1998-2003 & 26 & Unclear & 53.9 & $\begin{array}{l}\text { Mean daily dose at start of therapy: } \\
34 \mathrm{mg} \text { (SD 9.8, range } 20-50 \text { mg/day) } \\
\text { Mean duration: } 20 \text { months (SD 12) }\end{array}$ \\
\hline
\end{tabular}

$S D=$ standard deviation

pemphigoid index date was determined The proportion of prednisolone users who may have been prescribed prednisolone for an alternative indication was determined (that is, people with a Read code for an alternate indication and a prescription for oral prednisolone in the 12 months preceding bullous pemphigoid).

For each prednisolone user, the number of prescriptions, total follow-up time, followup time on prednisolone, and proportion of follow-up on prednisolone were determined. The duration of continuous exposure, defined as prescriptions with < 15 days between the end of one and the start of the next, was determined for each patient. The number of periods of continuous exposure were determined for each patient and summarised across the population. The proportion continuously exposed for longer than 3 months, 1 year, 3 years, 5 years, and 10 years were determined. For these, the denominator included only people with follow-up longer than the duration of interest (that is, longer than 3 months, 1 year, 3 years, 5 years, and 10 years, respectively).

Finally, the doses of oral prednisolone were examined. The median daily dose for all prescriptions was determined. The proportion of prednisolone users prescribed $\geq 10 \mathrm{mg} /$ day, $\quad \geq 20 \mathrm{mg} /$ day, $\geq 30 \mathrm{mg} /$ day, $\geq 40 \mathrm{mg} /$ day, $\geq 50 \mathrm{mg} / \mathrm{day}$, and $\geq 60 \mathrm{mg} /$ day was determined. The cumulative dose of prednisolone throughout the whole observation period was calculated for each patient, and the median determined across the population. The average dose while on prednisolone was determined by dividing the cumulative dose by the duration of exposure.

A sample size calculation was not conducted as this was a descriptive study using all available data. Population summary measures were presented as the median (interquartile range [IQR]) of continuous variables or number (proportion) for each categorical measure. Analyses were conducted with Stata 16.

\section{RESULTS}

\section{Study population}

There were 4437 people with incident bullous pemphigoid in the study period (Figure 1). The 762 people with <6 months' follow-up after their index date were excluded from the study, of whom 499 died. A further 353 people without 12 months of data before their index date were also excluded. The study population therefore comprised 3322 people with incident bullous pemphigoid with at least 12 months of data before and 6 months of data after their index date. They were identified from 667 practices, with a median 
Figure 1. Identification of the study population of adults with incident bullous pemphigoid from the CPRD. CPRD = Clinical Practice Research Datalink.

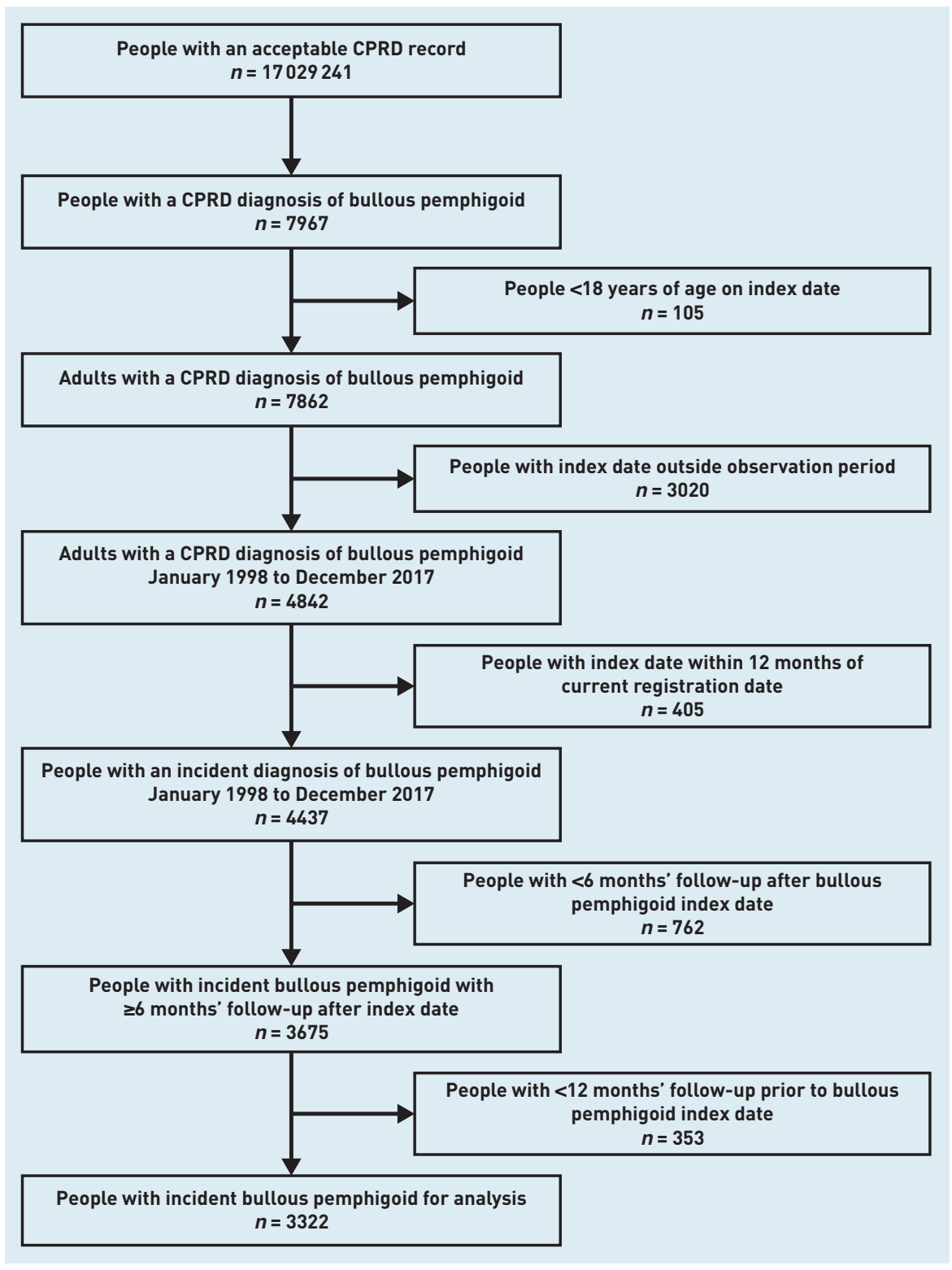

of four people with bullous pemphigoid for each GP practice.

The median age at first recording of bullous pemphigoid was 79.7 years (IQR 71.6-86.0) and 1858 (55.9\%) were female. Median duration of follow-up was 3.1 years (IQR 1.5-5.7) and ranged from 6 months to 18 years. Overall, the population represents 13758.2 person-years of follow-up (data not shown)

\section{Prednisolone users}

Overall, 2312 (69.6\%) people were prescribed oral prednisolone after their bullous pemphigoid index date. They were followed for 9506.0 person-years, of which 9.3 person-years were on prednisolone. The median number of months individuals spent on prednisolone was 10.6 (IQR 3.4-24.0), representing a median of $0.11 \%$ (IQR $0.02-$ 0.24) of their follow-up. The median number of prescriptions for prednisolone for each patient was 15 (IQR 8-26) (data not shown).

Of the prednisolone users, only 321 (13.9\%) had complete data for all prescriptions. For the remaining patients, the dose, start date, or treatment duration were imputed for at least one prescription. Eighty-eight (3.8\%) of the prednisolone users had a Read code for an alternate indication (for example, rheumatoid arthritis) and a prednisolone prescription in the 12 months before bullous pemphigoid (data not shown).

\section{Duration of continuous exposure}

The median number of periods of continuous exposure for a patient was 2 (IQR 1-3) and periods ranged from 1 day to 12 years 


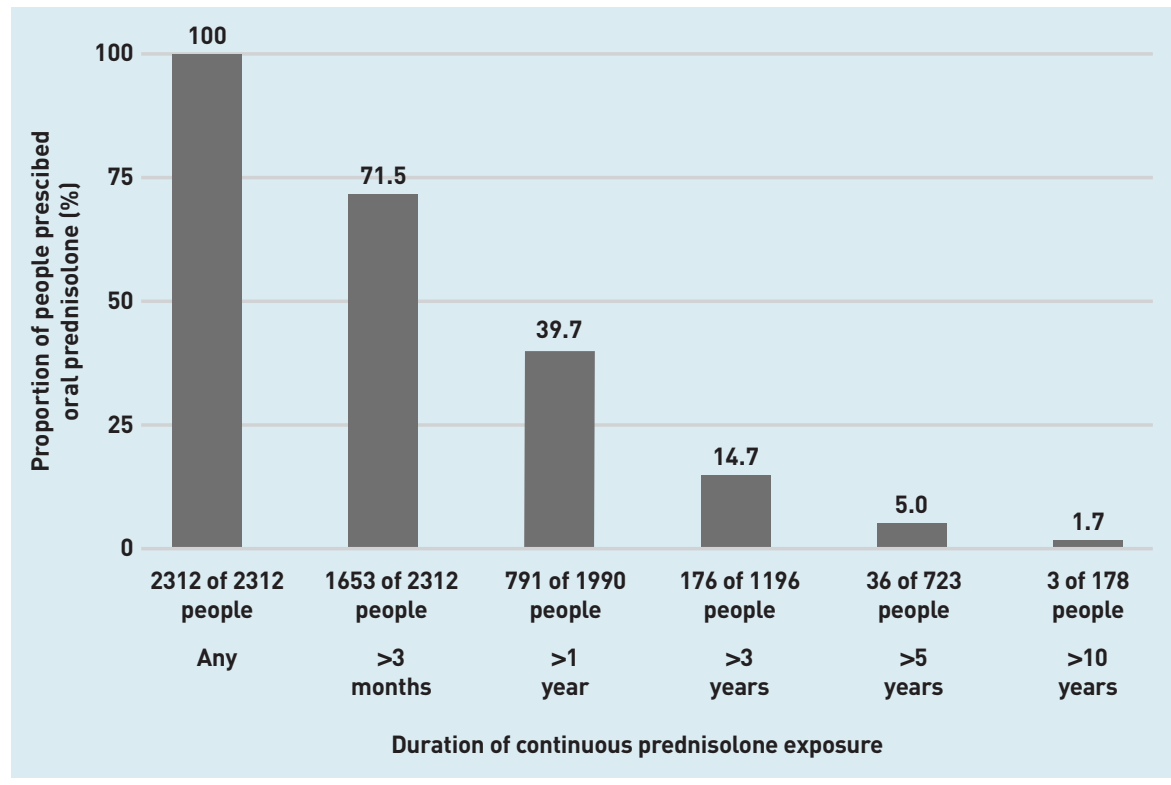

Figure 2. Proportion of prednisolone users continuously exposed to oral prednisolone for longer than 3 months, 1 year, 3 years, 5 years, and 10 years. ${ }^{a}$

athe denominator for duration includes only people with follow-up durations exceeding the duration of interest.

Figure 3. Proportion of prednisolone users prescribed a maximum daily dose of oral prednisolone $\geq 10 \mathrm{mg}$, $\geq 20 \mathrm{mg}, \geq 30 \mathrm{mg}, \geq 40 \mathrm{mg}, \geq 50 \mathrm{mg}, \geq 60 \mathrm{mg}$ at any point during the observation period. duration. Overall, $71.5 \%$ of prednisolone users were on prednisolone continuously for $>3$ months, $39.7 \%$ for $>1$ year, $14.7 \%$ for $>3$ years, $5.0 \%$ for $>5$ years, and $1.7 \%$ for $>10$ years (Figure 2).

\section{Oral prednisolone doses}

The median daily dose across all prescriptions was $10 \mathrm{mg} /$ day (IQR 5-13). There were 1721 (74.4\%) prednisolone users who were prescribed a maximum dose of $\geq 10 \mathrm{mg} /$ day, 941 (40.7\%) were prescribed $\geq 20 \mathrm{mg} /$ day, $420(18.2 \%) \geq 30 \mathrm{mg} /$ day, 153 $(6.6 \%) \geq 40 \mathrm{mg} /$ day, $87(3.8 \%) \geq 50 \mathrm{mg} /$ day and $44(1.9 \%) \geq 60 \mathrm{mg} /$ day (Figure 3) at any point during the observation period.

The median cumulative dose during followup was 2974 mg (IQR 1059-6456). Focusing

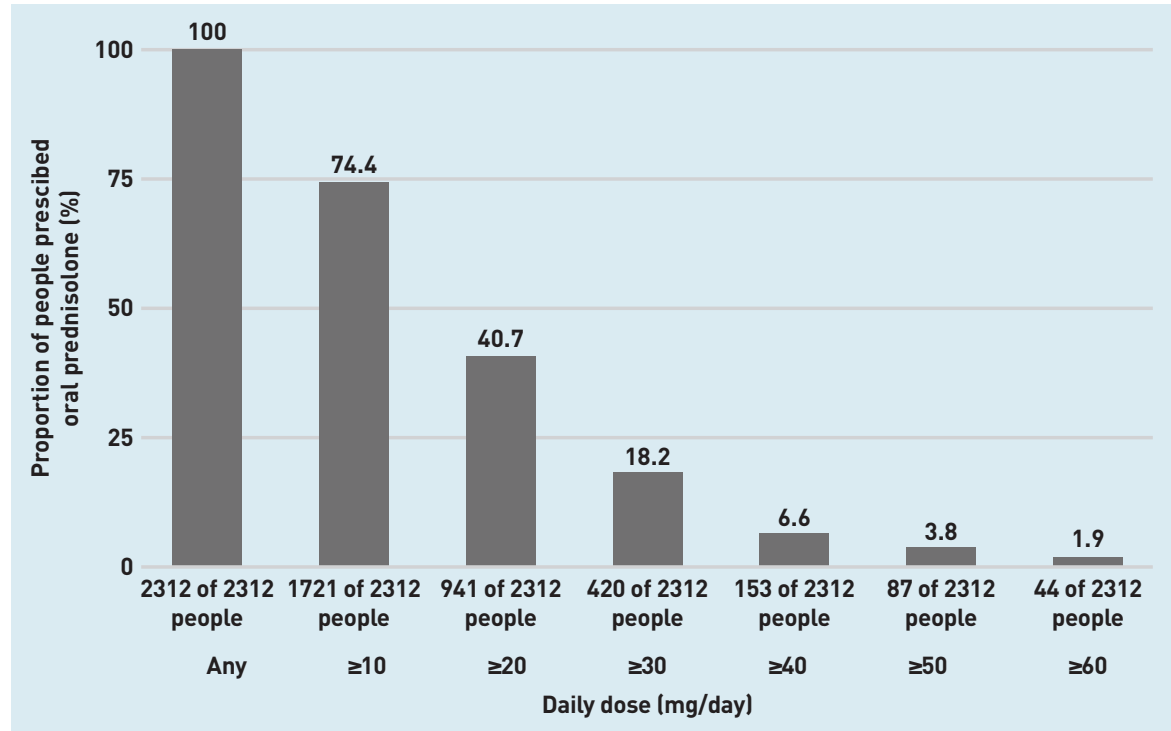

only on the duration of follow-up where the person was on a prednisolone prescription, the average daily dose was $<2.5 \mathrm{mg} /$ day for $11(0.5 \%)$ people, $2.5-5.0 \mathrm{mg} /$ day for 152 (6.6\%) people, $5.0-7.5 \mathrm{mg} /$ day for 351 (15.2\%) people, and $>7.5 \mathrm{mg} /$ day for $1798(77.8 \%)$ people (data not shown).

\section{DISCUSSION \\ Summary}

This study explored oral prednisolone prescribing for people with bullous pemphigoid in UK primary care. Of all people with new diagnoses of bullous pemphigoid identified from 1998 to 2017, 69.6\% were prescribed oral prednisolone in primary care following their diagnosis. Under the assumption that the initial high-dose regimens of prednisolone are more likely to be issued in dermatology clinics rather than in primary care, and ongoing prescriptions may not exclusively be issued in primary care, these findings likely underestimate both the duration of exposure and dosages of prednisolone, and should be viewed as the minimum exposure.

This study found that $71.5 \%$ of prednisolone users were exposed to prednisolone continuously for $>3$ months, and $39.7 \%$ were on prednisolone for $>1$ year. A small subset (1.7\%) were on prednisolone continuously for $>10$ years. Most patients $(74.4 \%)$ received daily doses $\geq 10 \mathrm{mg} /$ day at some point. The prescriptions totalled a median cumulative dose of $2974 \mathrm{mg}$ throughout the study period and, for $77.8 \%$ of the patients, an average daily dose of $>7.5 \mathrm{mg} /$ day during active periods of prescriptions.

Despite this study only presenting the minimum estimated exposure, these levels are sufficient to place people with bullous pemphigoid at risk of corticosteroidassociated adverse events. ${ }^{31,32}$ Strict monitoring and proactive management are required to minimise the risks to this population.

\section{Strengths and limitations}

Strengths of the present work include a large sample size, people with bullous pemphigoid identified from a source population that is broadly representative of the $\mathrm{UK}^{23}$ and the implementation of validated methods for identifying bullous pemphigoid and preparing the prescription data. The algorithm used to identify people with bullous pemphigoid has a positive predictive value of $93.2 \%,{ }^{27}$ thus indicating that the population analysed likely have bullous pemphigoid. The approach to preparing the prescriptions is validated and 
shown to accurately classify current oral corticosteroid status (on/off) for $86 \%$ of patients. ${ }^{29}$ Daily dose estimates generated from this approach are imprecise but not significantly biased, with a mean absolute difference in estimated and reported doses of 3.2 (standard deviation [SD] 4.2) mg/day. ${ }^{29}$ Finally, the authors of the current study believe it largely comprises individuals who were prescribed prednisolone for bullous pemphigoid rather than for other indications. Only 3.8\% of the prednisolone users had: 1) a record for an alternative indication for oral prednisolone; and 2) a prescription for oral prednisolone in the 12 months preceding bullous pemphigoid.

Limitations largely relate to the nature of the data used. First, although validated approaches for identifying patients and exposure were used, the findings may be subject to misclassification and measurement error. This is further compounded by the large proportion of missing data, affecting at least one prescription for $86.1 \%$ of people. Second, only prescriptions issued in primary care could be examined. As a result, it was only possible to present the minimum estimated exposure to prednisolone. In addition, the absence of information regarding the timing and duration of secondary care follow-up meant that this study could not describe the interplay between primary and secondary care prescribing of prednisolone. Third, it was not possible to capture and describe tapering regimens for prednisolone because of insufficient granularity in the data. Fourth, only oral prednisolone was examined and other systemic oral corticosteroids were not considered, such as betamethasone, and the study may therefore have underestimated total corticosteroid exposure. Finally, exclusion of people with $<6$ months' follow-up may have limited the external validity of the sample as death was the commonest reason for insufficient follow-up. However, it was felt that including people with $<6$ months' follow-up would artificially lower the estimated exposure to prednisolone as there was insufficient time for the prescriptions to pass from dermatology clinics to general practice.

\section{Comparison with existing literature}

To the authors' knowledge, this is the first population-based cohort study to examine the prescribing patterns of oral prednisolone for bullous pemphigoid in UK primary care. Recent evidence on oral corticosteroid use for bullous pemphigoid in the UK is based on a national audit completed by members of the British
Association of Dermatologists. In this, $85.5 \%(n=448 / 524)$ of those with bullous pemphigoid diagnoses were prescribed an oral corticosteroid by their dermatologist at some point during their management. ${ }^{33}$ The current study found that a more modest $69.6 \%$ of people are prescribed prednisolone in primary care, although this discrepancy may be largely attributed to the different settings. The higher proportion from the British Association of Dermatologists audit suggests that some people are exposed to prednisolone only in secondary, and not primary, care. It may be that these people commence oral prednisolone, which is then stopped in favour of an alternative treatment, because of disease resolution, or death. Alternatively, they may continue to be prescribed oral corticosteroids in secondary care.

Worldwide, several studies have reported oral prednisolone use in people with bullous pemphigoid. The current findings are largely in keeping with the proportion of prednisolone users in the previous literature, although with substantially lower doses than elsewhere (Table 1). Again, this may be because of differences in the setting and timing of prescriptions (that is, initial versus long-term treatment). In clinical practice, oral corticosteroids are used with a slowly reducing regimen for many months. Previous studies have captured the high initial doses prescribed. This work has extended beyond this initial period and captured high maximum doses ( $\geq 60 \mathrm{mg}$ / day in some) potentially indicative of initial doses and lower maintenance doses (for example, median daily doses $<10 \mathrm{mg} /$ dayl, potentially reflecting tapering regimens. Further interpretation of earlier evidence is hindered by the small population sizes and the largely hospital-based setting of previous research that generally did not extend beyond the initial management.

\section{Implications for research and practice}

Those with bullous pemphigoid are a clinically vulnerable group because of their older age (median age: 79.7 years) and significant comorbidities, including hypertension, diabetes mellitus, heart failure, and osteoporosis. ${ }^{34}$ There is therefore a need for careful consideration of additional risks for this population. There is evidence of a dose-dependent relationship between the cumulative dose of prednisolone and sleeping problems, acne, skin bruising, mood problems, cataracts, hyperglycaemia, and bone fractures. ${ }^{35}$ Focusing specifically on fracture risk, a daily dose of $7.5 \mathrm{mg} /$ day approximately 


\section{Funding}

This study presents independent research funded by the National Institute for Health Research (NIHR) under its Research for Patient Benefit Programme lgrant reference number: PB-PG-0817-20033). The views expressed are those of the author(s) and not necessarily those of the NIHR or the Department of Health and Social Care. In addition, Sinead M Langan was funded by a Wellcome Senior Clinical Fellowship in Science (reference number: 205039/Z/16/Z) during the conduct of the study. The funders had no involvement in the study design; collection, analysis, and interpretation of the data; writing of the report; or the decision to submit for publication.

\section{Ethical approval}

The present study was approved by the Independent Scientific Advisory Committee for the Clinical Practice Research Datalink (CPRD) (ISAC protocol number: 18_224).

\section{Provenance}

Freely submitted; externally peer reviewed.

\section{Competing interests}

Monica SM Persson, Karen E Harman, Kim S Thomas, Joanne R Chalmers, and Sonia Gran had financial support from NIHR and Sinead M Langan from the Wellcome Trust for the submitted work. Julia HippisleyCox is an unpaid director for QResearch, a primary care database similar to CPRD, which is a collaboration between the University of Oxford and EMIS Health Ithe leading commercial supplier of the GP NHS computer system). Yana Vinogradova has declared no competing interests.

\section{Acknowledgements}

The authors thank the members of the patient and public involvement steering group for their input to this project: Isobel Davies, Ingrid Thompson, Jag Barha, and Penny Standen.

\section{Open access}

This article is Open Access: CC BY 4.0 licence (http://creativecommons.org/ licences/by/4.0/).

\section{Discuss this article}

Contribute and read comments about this article: bjgp.org/letters

doubles the chance of developing a hip and vertebral fracture compared with $<2.5 \mathrm{mg} /$ day. ${ }^{32}$ This risk is evident even within 3-6 months of starting. ${ }^{31}$ As such, clinicians are exposing people with bullous pemphigoid to substantial iatrogenic risks as a result of prednisolone prescribing. Although these risks are outweighed in the short term by the urgent need to control the disease, this work shows that the exposure to prednisolone extends beyond the initial regimens prescribed in dermatology clinics.

Although GPs will often not be involved in the initial aggressive management of bullous pemphigoid, they may be tasked with prednisolone prescribing in the longer term. The authors urge clinicians to be mindful that this population, who may already be frail because of their age and significant comorbidities, may be on large doses of prednisolone for substantial periods of time. Strict monitoring and careful consideration of prophylactic treatments, such as bone-protection therapies, are essential for their long-term management. In addition, conversations between primary and secondary care should take place to consider steroid-sparing alternative treatments such as doxycycline. In 2017, doxycycline was shown to be non-inferior to oral corticosteroids for the management of bullous pemphigoid. ${ }^{8}$ This will likely have an impact on clinicians' practices, but such changes will not have been captured by the present work lobservation period 19982017). Further research may be needed to re-explore systemic steroid prescribing in patients post-2017.

Future research should also expand on this current study to examine steroidrelated outcomes (for example, hip and pelvis fractures) in people with bullous pemphigoid, and to determine whether adequate monitoring and prescription of prophylactic treatment (for example, bisphosphonates) occur. 


\section{REFERENCES}

1. Persson M, Harman $K$, Vinogradova $Y$, et al. Incidence, prevalence and mortality of bullous pemphigoid in England 1998-2017: a population-based cohort study. Br J Dermatol 2021; 184(1): 68-77.

2. Persson MSM, Harman KE, Thomas KS, et al. Using electronic health records to inform trial feasibility in a rare autoimmune blistering skin disease in England. BMC Med Res Methodol 2021; 21(1): 1-7.

3. Narla S, Silverberg JI. Associations of pemphigus or pemphigoid with autoimmune disorders in US adult inpatients. J Am Acad Dermatol 2020; 82(3): 586-595

4. Kridin K, Ludwig RJ, Schonmann Y, et al. The bidirectional association between bullous pemphigoid and psoriasis: a population-based cohort study. Front Med (Lausanne) 2020; 7: 511.

5. Bech R, Kibsgaard L, Vestergaard C. Comorbidities and treatment strategies in bullous pemphigoid: an appraisal of the existing litterature. Front Med (Lausanne) 2018; 5: 238.

6. Wojnarowska F, Kirtschig G, Highet A, et al. Guidelines for the management of bullous pemphigoid. Br J Dermatol 2002; 147(2): 214-221.

7. Venning V, Taghipour K, Mohd Mustapa M, et al. British Association of Dermatologists' guidelines for the management of bullous pemphigoid 2012. Br J Dermatol 2012; 167(6): 1200-1214

8. Williams HC, Wojnarowska F, Kirtschig G, et al. Doxycycline versus prednisolone as an initial treatment strategy for bullous pemphigoid: a pragmatic, non-inferiority, randomised controlled trial. Lancet 2017; 389(10079): 1630-1638.

9. Joly P, Roujeau J-C, Benichou J, et al. A comparison of oral and topical corticosteroids in patients with bullous pemphigoid. N Engl J Med 2002; 346(5): 321-327.

10. Joint Formulary Committee. British National Formulary: prednisolone. 2020. https://bnf.nice.org.uk/drug/prednisolone.html laccessed 24 Sep 2021).

11. Chovatiya R, Silverberg Jl. Association of pemphigus and pemphigoid with osteoporosis and pathological fractures. Arch Dermatol Res 2020; 312(4): 263-271.

12. Balestri R, Odorici $G$, Patrizi $A$, et al. Survey of bullous pemphigoid in an Italian university hospital: clinical-epidemiological characteristics and follow-up. $G$ Ital Dermatol Venereol 2018; 153(5): 613-618

13. Kremer N, Zeeli T, Sprecher E, Geller S. Failure of initial disease control in bullous pemphigoid: a retrospective study of hospitalized patients in a single tertiary center. Int J Dermatol 2017; 56(10): 1010-1016.

14. Zhang L-M, Wu J, Xiao T, et al. Treatment and mortality rate of bullous pemphigoid in China: a hospital-based study. Eur J Dermatol 2013; 23(1): 94-98.

15. Esmaili N, Hallaji Z, Soori T, Davatchi CC. Bullous pemphigoid in Iranian patients: a descriptive study on 122 cases. Acta Med Iran 2012; 50(5): 335-338.

16. Kulthanan $\mathrm{K}$, Chularojanamontri $\mathrm{L}$, Tuchinda $\mathrm{P}$, et al. Prevalence and clinical features of Thai patients with bullous pemphigoid. Asian Pac J Allergy Immunol 2011; 29(1): 66-72.
17. Serwin AB, Bokiniec E, Piascik M, et al. Epidemiological and clinical analysis of pemphigoid patients in northeastern Poland in 2000-2005. Med Sci Monit 2007; 13(8): CR360-CR364.

18. Nanda A, Al-Saeid K, Al-Sabah H, et al. Clinicoepidemiological features and course of 43 cases of bullous pemphigoid in Kuwait. Clin Exp Dermatol 2006; 31(3): 339-342.

19. Tan S-K, Tay Y-K. Bullous pemphigoid: profile and outcome in a series of 100 cases in Singapore. J Dermatol Dermatol Surg 2018; 22(1): 12-15.

20. Wong SN, Chua SH. Bullous pemphigoid seen at the National Skin Centre: a 2-year retrospective review. Ann Acad Med Singapore 2002; 31(2): 170-174.

21. Chang $Y$, Liu H, Wong C. Bullous pemphigoid - a report of 86 cases from Taiwan. Clin Exp Dermatol 1996; 21(1): 20-22.

22. Garcia-Doval I, Conde Taboada A, Cruces Prado MJ. Sepsis associated with dermatologic hospitalization is not the cause of high mortality of bullous pemphigoid in Europe. J Invest Dermatol 2005; 124(3): 666-667.

23. Herrett E, Gallagher AM, Bhaskaran K, et al. Data resource profile: Clinical Practice Research Datalink (CPRD). Int J Epidemiol 2015; 44(3): 827-836.

24. Chisholm J. The Read clinical classification. BMJ 1990; 300(6732): 1092.

25. Herrett E, Thomas SL, Schoonen WM, et al. Validation and validity of diagnoses in the General Practice Research Database: a systematic review. Br J Clin Pharmacol 2010; 69(1): 4-14

26. Benchimol El, Smeeth L, Guttmann A, et al. The REporting of studies Conducted using Observational Routinely-collected health Data (RECORD) statement. PLoS Med 2015; 12(10): e1001885.

27. Persson MS, Harman KE, Vinogradova Y, et al. Validation study of bullous pemphigoid and pemphigus vulgaris recording in routinely collected electronic primary healthcare records in England. BMJ Open 2020; 10(7): e035934.

28. Pye SR, Sheppard T, Joseph RM, et al. Assumptions made when preparing drug exposure data for analysis have an impact on results: an unreported step in pharmacoepidemiology studies. Pharmacoepidemiol Drug Saf2018; 27(7): 781-788.

29. Joseph RM, van Staa TP, Lunt M, et al. Exposure measurement error when assessing current glucocorticoid use using UK primary care electronic prescription data. Pharmacoepidemiol Drug Saf 2019; 28(2): 179-186.

30. Kuan V, Denaxas S, Gonzalez-Izquierdo A, et al. A chronological map of 308 physical and mental health conditions from 4 million individuals in the English National Health Service. Lancet Digit Health 2019; 1(2): e63-e77.

31. Van Staa T, Leufkens H, Cooper $\mathrm{C}$. The epidemiology of corticosteroid-induced osteoporosis: a meta-analysis. Osteoporosis Int 2002; 13(10): 777-787.

32. Van Staa T-P, Leufkens $H$, Abenhaim $L$, et al. Use of oral corticosteroids in the United Kingdom. QJM 2000; 93(2): 105-111.

33. Smith H, Mohd Mustapa M, Cheung S, de Berker D. National audit on the management of bullous pemphigoid. Clin Exp Dermatol 2020; 45(3): 289-294.

34. Persson MSM, Harman KH, Thomas K, et al. Using electronic health records to inform trial feasibility in a rare autoimmune blistering skin disease in England. BMC Med Res Methodol 2021; 21(1): 1-7.

35. Curtis JR, Westfall AO, Allison J, et al. Population-based assessment of adverse events associated with long-term glucocorticoid use. Arthritis Care Res 2006; 55(3): 420-426. 